Gut, 1989, 30, 1179-1186

Alimentary tract

\title{
Oesophageal manometry during eating in the investigation of patients with chest pain or dysphagia
}

\author{
P J HOWARD, A PRYDE, AND R C HEADING \\ From the Department of Medicine, Royal Infirmary of Edinburgh, Edinburgh
}

SUMMARY Dysphagia is a frequent cause of referral for oesophageal manometry although the motor response to eating is not routinely studied. We examined symptoms and oesophageal motor patterns in response to eating bread in 30 patients with either gastro-oesophageal reflux $(n=20)$, or normal oesophageal function tests $(n=10)$. No patient experienced symptoms while swallowing water but one complained of heartburn and one developed symptomatic oesophageal 'spasm' during eating. In eight further patients, pain or dysphagia which occurred with swallowing bread was associated with aperistalsis. Comparing asymptomatic and symptomatic periods, there was a slight increase in mean swallow frequency from 7.5 (0.79) (SEM) to 9.0 (1.17) swallows per minute (NS; $n=10)$. The mean number of aperistaltic swallows increased from $4 \cdot 5(0.96)$ per minute to $6 \cdot 2(1 \cdot 30)(p<0 \cdot 01 ; n=10)$. Aperistalsis during symptoms was mainly caused by non-conducted swallows rather than synchronous contractions (mean $5 \cdot 8(1 \cdot 45)$ per minute compared with $1 \cdot 2(0 \cdot 44)$ ). Aperistalsis can be produced by rapid swallowing in the normal oesophagus through 'deglutitive inhibition'. These results suggest that some patients experience dysphagia associated with aperistalsis perhaps as a response to increased frequency of swallowing. Functional abnormalities of this nature will not be detected by conventional oesophageal manometry.

There is general agreement that motor abnormalities elicited during conventional oesophageal manometry are seldom accompanied by symptoms. ${ }^{1-1}$ In consequence, various 'stress tests' have been devised to provoke oesophageal dysmotility and reproduce symptoms in the laboratory, in the belief that only by showing the simultaneous occurrence of dysmotility and symptoms can a cause and effect relationship be confidently identified. Such tests have included ice water swallows, intraoesophageal acid instillation," intravenous bethanechol, ${ }^{7}$ edrophonium, ${ }^{17 x-10}$ pentagastrin," and ergometrine. ${ }^{12} 13$ None of these procedures has proved wholly satisfactory, however, and interest is now turning to the possibility that prolonged ambulatory motility studies may be more rewarding. 1415

Despite the fact that the symptom of dysphagia is often related to eating, there has been surprisingly

Address for correspondence: Dr P J Howard, Department of Medicine. The Royal Infirmary of Edinburgh, Edinburgh EH3 9YW.

Accepted for publication 17 January 1989. little investigation of oesophageal motility while eating normal food. We therefore investigated the effects of eating on oesophageal motility patterns and symptoms in 30 patients referred for oesophageal function studies. Ten had normal oesophageal tests by conventional criteria (group A), whilst the remaining 20 had evidence of gastro-oesophageal reflux (group B).

\section{Methods}

PATIENTS

Patients were selected from those referred for oesophageal function tests. All underwent upper gastrointestinal endoscopy, radionuclide oesophageal transit measurements, ambulatory oesophageal $\mathrm{pH}$ monitoring and manometric studies.

Radionuclide oesophageal transit measurements were performed in the supine position, using $10 \mathrm{ml}$ water labelled with ${ }^{99 \mathrm{~m}} \mathrm{Tc}$ as previously described. ${ }^{16}$ A transit time of less than 15 seconds was taken as normal. 
All medication was stopped 48 hours before either manometry or 23 hour $\mathrm{pH}$ studies were performed. Ambulatory 23 hour $\mathrm{pH}$ monitoring was done using a glass $\mathrm{pH}$ electrode with a combined internal reference electrode (Radiometer, Copenhagen). This was positioned $3 \mathrm{~cm}$ above the upper border of the manometrically defined lower oesophageal sphincter. No restrictions were placed upon the patient's usual eating, drinking, or smoking habits. All patients were given a diary card on which to record the times of eating and drinking, the times spent recumbent and the occurrence of symptoms. A distal oesophageal acid exposure time of $>7 \%$ of total recording time was considered abnormal.'

Distal oesophageal manometry was done after an overnight fast, using an Arndorfer system and a standardised technique. ${ }^{17}$ Lower oesophageal sphincter pressure was assessed by three 'rapid pull throughs'. Sphincter relaxation in response to dry swallows was assessed during a standard 'station pull through'. Distal oesophageal motility was measured by three recording channels situated 5,10 , and $15 \mathrm{~cm}$ above the lower oesophageal sphincter using 15 swallows of $5 \mathrm{ml}$ of water at room temperature administered by a syringe at $>15$ second intervals. A fourth channel, situated $20 \mathrm{~cm}$ above the lower sphincter, recorded pressures in the upper oesophagus or sphincter and served as a swallow sensor.

After conventional manometry, the recording catheter was left in situ and the patients were asked to eat a slice of buttered bread whilst lying semirecumbent. Water was allowed as required. Swallows were identified by the swallow artefact produced in the proximal recording channel and confirmed visually and patients were asked to report any symptoms.

Of a total of 50 patients examined, 10 patients were identified who had normal endoscopy, conventional manometry and transit times and a total acid exposure time of $<7.0 \%$. These were designated as group A. Twenty patients were identified with gastro-oesophageal reflux (acid exposure time of more than $7 \%$ of recording time and/or endoscopic evidence of oesophagitis) - group B.

EXPRESSION AND ANALYSIS OF RESULTS

The mean amplitude $(\mathrm{mmHg})$ of the first 10 contractions in the distal channel in response to swallowing water was measured. 'Double swallows' were excluded. Manometric abnormality was classified according to the system of Benjamin et al using normal values volunteers defined by Richter et $a l^{17}$ using a similar technique.

Peristaltic waves were defined as contractions showing a continuous progression down the oesophagus and recorded sequentially in all four channels. Contractions that had a simultaneous onset within the distal three channels were regarded as synchronous. Non-conducted swallows were those that failed to produce a recordable pressure in the distal channel, above respiratory variation (approximately $20 \mathrm{mmHg}$ ). Swallows which either failed to conduct, or produced synchronous contractions in the distal oesophagus were considered aperistaltic.

Comparisons were made between swallow intervals, contraction amplitudes, the proportion of nonconducted swallows and the percentages of peristaltic and synchronous contractions in response to swallowing water and bread within each group (intragroup comparisons). The same parameters were also compared between the two groups for both water and bread swallows (intergroup comparisons).

\section{ASS ESSMENT OF SYM PTOMS}

In those patients who experienced symptoms while eating, one minute periods starting 30 seconds before the reporting of symptoms, were compared with an arbitrary control period of one minute starting 60 seconds after the commencement of the recording. (If symptoms occurred during this period, the first continuous one minute symptom free interval was taken as the control period.) Any qualitative changes in motor patterns were noted. Swallow frequency, contraction amplitudes and the percentage of aperistaltic swallows during the control and pain periods were compared.

\section{STATISTICAL ANALYSIS}

Differences in swallow frequencies and contraction amplitudes were analysed by Student's $t$ test for matched or unmatched pairs, respectively. Differences in the percentage of synchronous and nonconducted swallows were analysed by the Wilcoxon's rank-sum test, as the data were not normally distributed.

\section{Results}

Clinical details of the patients and the results of their investigations are outlined in Table 1.

The mean ages of patients in the control and reflux groups were $44(10.9)$ SD years and $49.8(13.7)$ years, respectively. The male to female ratio was $3: 2$ in the control and 2:3 in the reflux group. All patients presented with epigastric and/or chest pain or discomfort. Three of the patients in group $\mathrm{A}$ had odynophagia and two had dysphagia. Ten of the reflux patients (group B) complained of odynophagia and 11 of dysphagia. Only one of the reflux group had a total acid exposure time of less than $7 \%(6.0 \%)$, though she had endoscopic evidence of oesophagitis. In the reflux group, seven patients had oesophagitis and two more had a Barrett's oesophagus. Four of 
Table 1 Clinical details of patients studied

\begin{tabular}{|c|c|c|c|c|c|c|c|c|c|}
\hline $\begin{array}{l}\text { Control } \\
\text { group }\end{array}$ & Sex & Age & \multicolumn{3}{|c|}{$\begin{array}{l}\text { Presenting } \\
\text { complaints }\end{array}$} & \multirow{2}{*}{$\frac{R T T}{\text { Normal }}$} & \multirow{2}{*}{$\frac{A E T(\%)}{3 \cdot 2}$} & \multirow{2}{*}{$\begin{array}{l}\text { Manometry } \\
\text { Normal }\end{array}$} & \multirow{2}{*}{$\begin{array}{l}\text { Endoscopy } \\
\text { Normal }\end{array}$} \\
\hline 1 & $\mathrm{~F}$ & 47 & $P$ & & & & & & \\
\hline 2 & $\mathbf{M}$ & 24 & $\mathbf{P}$ & $\mathrm{O}$ & & Normal & $2 \cdot 7$ & Normal & Normal \\
\hline 3 & $\mathbf{M}$ & 31 & $P$ & $\mathrm{O}$ & & Normal & $2 \cdot 3$ & Normal & normal \\
\hline 4 & $\mathrm{M}$ & 42 & $\mathrm{P}$ & $\mathrm{O}$ & $\mathrm{D}$ & Normal & $2 \cdot 7$ & Normal & Normal \\
\hline 5 & $\mathrm{~F}$ & 58 & $P$ & & & Normal & 1.9 & Normal & Normal \\
\hline 7 & $\mathrm{M}$ & 41 & $\mathrm{P}$ & & & Normal & $4 \cdot 7$ & Normal & Normal \\
\hline 8 & $\mathbf{M}$ & 40 & $\mathrm{P}$ & & & Normal & $2 \cdot 9$ & Normal & Normal \\
\hline 9 & $\mathrm{~F}$ & 52 & $P$ & & $\mathrm{D}$ & Normal & $3 \cdot 8$ & Normal & Normal \\
\hline 10 & $\mathbf{M}$ & 47 & $\mathrm{P}$ & & & Normal & $4 \cdot 2$ & Normal & Normal \\
\hline \multicolumn{10}{|c|}{ Reflux group } \\
\hline 11 & $\mathrm{~F}$ & 60 & $\mathbf{P}$ & & $\mathrm{D}$ & Prolonged & $11 \cdot 7$ & Normal & Healed DU \\
\hline 12 & $\mathrm{M}$ & 48 & $P$ & & & Normal & $9 \cdot 1$ & Normal & Duodenitis \\
\hline 14 & $\mathrm{~F}$ & 55 & $\mathrm{P}$ & $\mathrm{O}$ & $\mathrm{D}$ & Prolonged & $9 \cdot 2$ & NSMD & Normal \\
\hline 15 & $F$ & 56 & $\mathrm{P}$ & $\mathrm{O}$ & & Prolonged & $7 \cdot 1$ & NSMD & Barrett's \\
\hline 16 & $\mathbf{M}$ & 72 & $\mathrm{P}$ & $\mathrm{O}$ & & Normal & $14 \cdot 2$ & Normal & Oesophagitis \\
\hline 17 & $\mathrm{~F}$ & 54 & $P$ & & $\mathrm{D}$ & Normal & $6 \cdot 0$ & Normal & Oesophagitis \\
\hline 18 & $\mathbf{M}$ & 38 & $P$ & $\mathrm{O}$ & & Normal & $10 \cdot 0$ & Normal & Normal \\
\hline 19 & $\mathbf{M}$ & 34 & $\mathrm{P}$ & $\mathrm{O}$ & $\mathrm{D}$ & Normal & $7 \cdot 6$ & Normal & Normal \\
\hline 20 & $F$ & 25 & $\mathrm{P}$ & $\mathrm{O}$ & $\mathrm{D}$ & Normal & $9 \cdot 3$ & Normal & Normal \\
\hline 21 & $\mathrm{M}$ & 29 & $\mathbf{P}$ & $\mathrm{O}$ & $\mathrm{D}$ & Normal & $15 \cdot 6$ & Normal & Oesophagitis \\
\hline 22 & $F$ & 20 & $\mathbf{P}$ & & & Normal & $9 \cdot 2$ & Normal & $\mathrm{HH}$ \\
\hline 23 & $\mathrm{~F}$ & 60 & $\mathbf{P}$ & & $\mathrm{D}$ & Prolonged & $25 \cdot 4$ & Normal & HH Oesophagitis \\
\hline 24 & $\mathrm{~F}$ & 60 & $P$ & & & Prolonged & $2 i) \cdot 2$ & NSMD & Oesophagitis \\
\hline 25 & $\mathrm{~F}$ & 58 & $\mathrm{P}$ & $\mathrm{O}$ & $\mathrm{D}$ & Prolonged & $10 \cdot 6$ & Spasm & HH Oesophagitis \\
\hline 26 & $\mathbf{M}$ & 48 & $\mathrm{P}$ & & $\mathrm{D}$ & Normal & $8 \cdot 6$ & Normal & Normal \\
\hline 27 & $F$ & 50 & $\mathrm{P}$ & $\mathrm{O}$ & & Prolonged & 45.9 & Spasm & НH \\
\hline 28 & $F$ & 61 & $P$ & & $\mathrm{D}$ & Normal & $11 \cdot 3$ & Normal & Normal \\
\hline 29 & $M$ & 55 & $\mathbf{P}$ & & & Normal & $10 \cdot 2$ & Normal & Normal \\
\hline
\end{tabular}

RTT: radionuclide transit time: AET: acid exposure time (\% of total recording time): NSMD: non-specific motility disorder: P: pain: $\mathrm{O}$ : odynophagia: D: dysphagia: $\mathrm{HH}$ : hiatus hernia.

Table 2 Oesophageal motor responses to water and bread swallows in groups $A$ and B (means (SEM)

\begin{tabular}{|c|c|c|c|c|c|c|}
\hline & \multicolumn{3}{|l|}{ Group $A$} & \multicolumn{3}{|l|}{ Group B } \\
\hline & $\begin{array}{l}\text { Water } \\
\text { swallows }\end{array}$ & $\begin{array}{l}\text { Bread } \\
\text { swallows }\end{array}$ & $p$ & $\begin{array}{l}\text { Water } \\
\text { swallows }\end{array}$ & $\begin{array}{l}\text { Bread } \\
\text { swallows }\end{array}$ & $p$ \\
\hline Swallow intervals (sec) & $20 \cdot 6(1 \cdot())$ & $11 \cdot 2(1 \cdot 3)$ & $<0 \cdot(0) 1$ & $18 \cdot 8(0 \cdot 6)$ & $10 \cdot 2(0 \cdot 7)$ & $<0 \cdot(001$ \\
\hline Contraction amplitudes $(\mathrm{mmHg})$ & $77 \cdot 9(8 \cdot 2)$ & $78 \cdot 3(12 \cdot 6)$ & NS & $67 \cdot 8(8 \cdot 5)$ & $63 \cdot 4(4 \cdot 5)$ & NS \\
\hline Non-conducted swallows $(\%)$ & $2 \cdot 0(1 \cdot 3)$ & $34 \cdot 2(5 \cdot 8)$ & $<0 \cdot() 1$ & $7 \cdot(0(2 \cdot 5)$ & $38 \cdot 1(4 \cdot 5)$ & $<0 \cdot(01$ \\
\hline$\%$ of swallows followed by aperistalsis & $2 \cdot 0(1 \cdot 3)$ & $47 \cdot 4(6 \cdot 4)$ & $<0 \cdot(01$ & $9 \cdot 5(4 \cdot 6)$ & $46 \cdot 7(5 \cdot 6)$ & $<0 \cdot 005$ \\
\hline
\end{tabular}

the reflux patients exhibited a non-specific motility disorder with low amplitude and/or non-conducted swallows and two had frequent synchronous contractions interspersed with normal peristalsis. Sphincteric relaxation was normal in all cases.

In four patients (all from group B) the proximal channel which acted as a 'swallow sensor', was located in the pharynx and swallow activity was readily identifiable. In 20 patients (seven group A; 13 group B), the proximal channel was in the upper oesophageal sphincter. In the remaining six patients (three group A; three group B) it lay within the cervical oesophagus. In these six patients, however, swallows were readily identified by a swallow artefact, consisting of a brief fall in pressure of approximately 5-10 $\mathrm{mmHg}$, or 'schluckatmung'. (This well described fall in pressure, which occurs simultaneously with a fall in intrathoracic pressure, 
is thought to be because of a short inspiration immediately preceding swallowing. ${ }^{18}$ )

Table 2 compares swallowing water and bread in groups $\mathrm{A}$ and $\mathrm{B}$.

In group $A$ patients, the mean swallow interval whilst eating the bread (11.2(1.3) SEM seconds) was less than that during conventional manometry $(20 \cdot 6$ $(1.0) ; p<0.001)$. Of course, swallow frequency during conventional manometry was fixed by the study protocol, whereas swallow rate during eating was determined by the patient. The percentage of swallows which were aperistaltic was greater after bread $(47.4 \%(6.4))$, than after water swallows $(2.0 \%(1.3) ; p<0.01)$. A similar pattern of results was seen in the patients in group $B$. The mean swallow interval while eating bread was less than after swallowing water $(10.2(0.7)$ compared with $18.8 \operatorname{secs}(0 \cdot 6) ; \mathrm{p}<0 \cdot 001)$. As in group $\mathrm{A}$, there was also a marked increase in the percentage of nonconducted and synchronous contractions after bread swallows, compared with swallowing water $(46.7 \%$ $(5 \cdot 6)$ and $9 \cdot 5 \%(4 \cdot 6, \mathrm{p}<0 \cdot 005)$.

Comparing patients in groups A and B (intergroup conparisons) no significant differences in swallow frequency or oesophageal motility were found.

ASSESSMENT OF DYSPHAGIA AND PAIN DURING SWALLOWING BREAD

Table 3 summarises the patients' symptoms during conventional manometry and whilst eating.
Table 3 Symptoms during conventional manometry with water swallows and while eating bread

\begin{tabular}{|c|c|c|c|c|}
\hline & \multicolumn{2}{|c|}{ Group $A(n=10)$} & \multicolumn{2}{|c|}{ Group $B(n=20)$} \\
\hline & $\begin{array}{l}\text { Water } \\
\text { swallows }\end{array}$ & $\begin{array}{l}\text { Bread } \\
\text { swallows }\end{array}$ & $\begin{array}{l}\text { Water } \\
\text { swallows }\end{array}$ & $\begin{array}{l}\text { Bread } \\
\text { swallows }\end{array}$ \\
\hline Pain alone & 0 & 1 & 0 & () \\
\hline Dysphagia alone & 0 & 0 & () & 6 \\
\hline Both pain and dysphagia & 0 & 0 & () & 3 \\
\hline
\end{tabular}

None of the patients from either group experienced symptoms during conventional manometry. There was a significant increase, however, in the number of patients who experienced symptoms during eating $\left(\chi^{2}=9.7 ; p<0.002\right)$. One patient in group A (patient 8 ) complained of heartburn whilst eating the bread, though without any apparent change in motility. Nine of the 20 patients in group B experienced dysphagia, which was always accompanied by a feeling of discomfort (patients 11, 14, 16, $17,18,20,21,26$, and 28 ). Only three patients, however, (numbers 16,17, and 26) complained of definite pain and dysphagia simultaneously, of whom one (patient 16), had an episode of oesophageal 'spasm' during symptoms (Fig. 1). In the remaining two, who experienced pain and dysphagia, and the remaining six with dysphagia alone, symptoms were associated with an increase in the percentage of

Fig. 1 Oesophageal manometry recorded at $13 \mathrm{~cm}$ (top), $8 \mathrm{~cm}$ (middle), and $3 \mathrm{~cm}$ (bottom) above the lower oesophageal sphincter in patient 16 showing 'spasm' while eating bread. Arrows indicate swallows. 


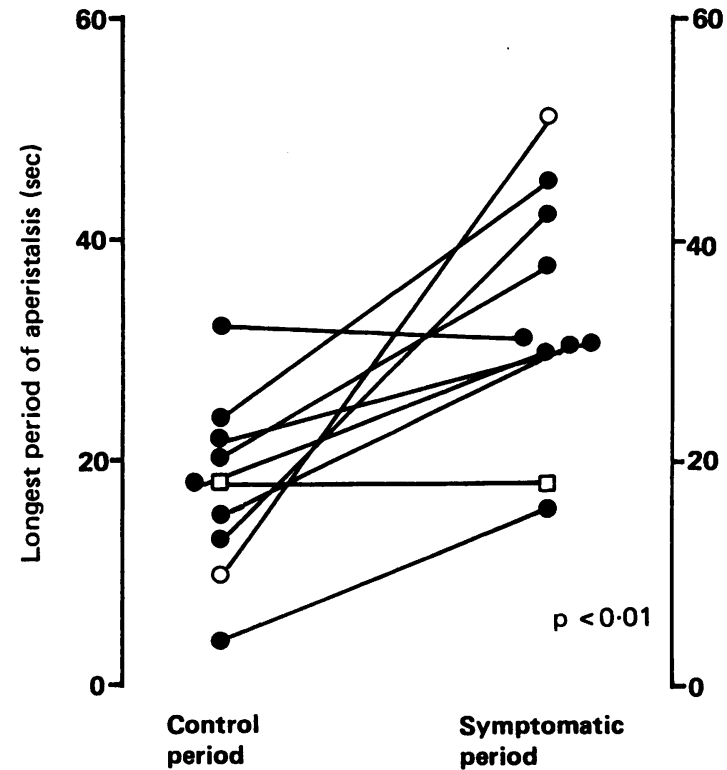

Fig. 2 Comparison of control and symptom periods in the 10 subjects who experienced symptoms while eating bread showing the longest interval during which there was no peristaltic activity. ( $\square$ ) denotes the patient who experienced 'heartburn' and (O) the patient who had oesophageal 'spasm'. aperistaltic swallows. Direct observation of the patients suggested that the aperistalsis preceded the perception of dysphagia or pain.

The findings in the 10 symptomatic patients are shown in Table 4 and Figure 2.

Mean swallow frequency during periods of pain or dysphagia was slightly increased compared with control periods (from 7.5 swallows per minute $(0 \cdot 79)$ to $9 \cdot 0(1 \cdot 17))$. Although this difference was not statistically significant $(p=0.44)$, significantly more swallows were aperistaltic during episodes of dysphagia, than during control periods $(77.4 \%(4 \cdot 7)$ compared to $53.1 \%(8.5): \mathrm{p}<0.01)$. The duration of periods of aperistalsis almost doubled from $17 \cdot 5(2 \cdot 5)$ seconds during the control, to $33.2(3.67)$ during the symptomatic periods $(\mathrm{p}<0.01)$.

An example of aperistalsis in association with dysphagia is shown in Figure 3 (patient 21). The three episodes of dysphagia experienced by this patient were all related to episodes of rapid swallowing. Figure 4 illustrates both the variation in swallow interval while eating the bread and the association between short swallow intervals and dysphagia.

\section{Discussion}

Two conclusions are immediately apparent from our results. First, that there are important differences in oesophageal motility while eating compared with
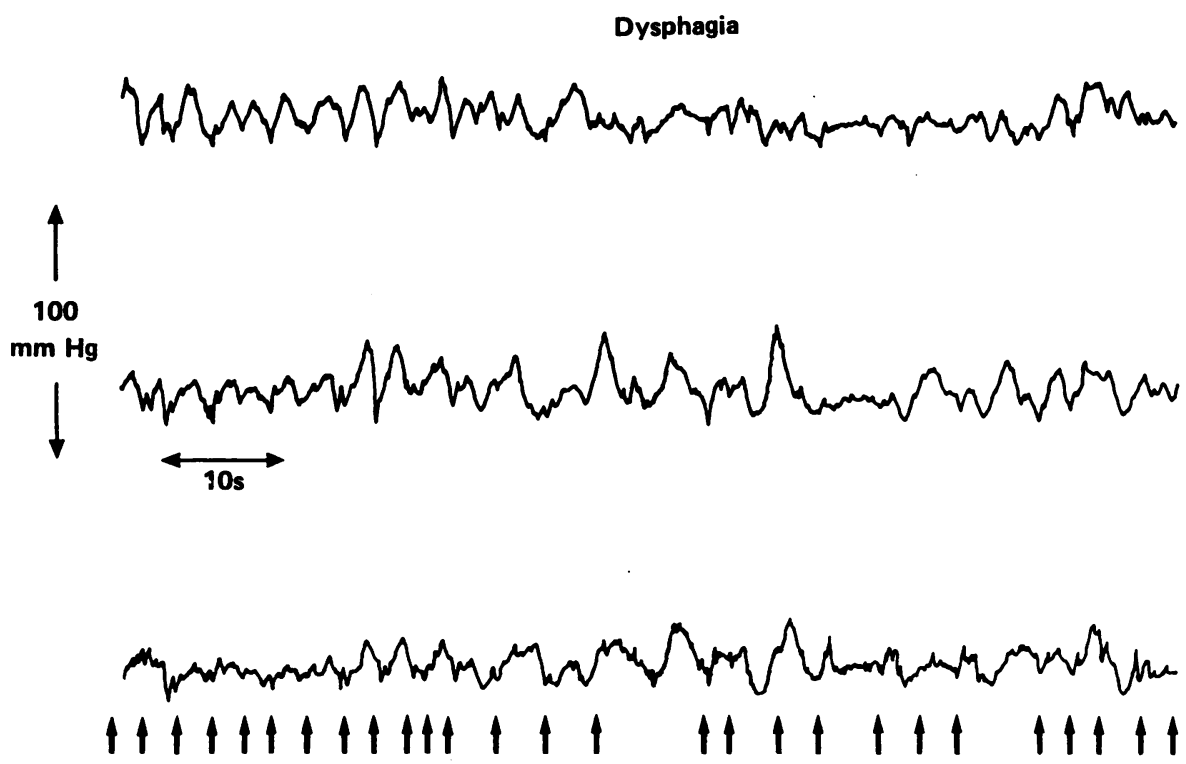

Fig. 3 Oesophageal manometry as recorded in Figure 1 showing lack of peristalsis associated with rapid swallowing (patient 21). Dysphagia was first reported at the point indicated. 
Table 4 Oesophageal motility in symptomatic patients. Comparison of one minute control periods during which patients were asymptomatic with one minute periods during which symptoms were reported

\begin{tabular}{|c|c|c|c|c|c|c|c|c|}
\hline \multirow{2}{*}{\multicolumn{2}{|c|}{$\begin{array}{l}\text { Swallows } \\
\text { (n) }\end{array}$}} & \multicolumn{3}{|c|}{ Control period } & \multirow[b]{2}{*}{$\begin{array}{l}\text { Swallows } \\
(n)\end{array}$} & \multicolumn{3}{|c|}{ Symptom period } \\
\hline & & Peri & Sync & $T I$ & & Peri & Sync & $T I$ \\
\hline & 3 & 3 & 0 & 0 & 7 & 3 & 4 & 0 \\
\hline & 10 & 2 & 0 & 8 & 10.7 & $2 \cdot 3$ & $0 \cdot 3$ & $8 \cdot 3$ \\
\hline & 5 & 2 & 0 & 3 & 4 & 0 & 3 & 1 \\
\hline & 10 & 3 & 1 & 7 & 11 & $2 \cdot 3$ & 0.3 & $8 \cdot 3$ \\
\hline & 11 & 2 & 0 & 9 & 10 & $1 \cdot 5$ & 0.5 & 8 \\
\hline & 8 & 4 & 1 & 3 & 7 & 2 & 2 & 2 \\
\hline & 8 & 4 & 0 & 4 & 8 & 3 & 0 & 5 \\
\hline & 8 & 3 & 0 & 5 & $17 \cdot 5$ & 1.75 & 0 & 15.75 \\
\hline & 6 & 3 & 3 & 0 & 6 & 0.8 & $0 \cdot 2$ & $5 \cdot 2$ \\
\hline & 6 & 4 & 1 & 0 & $8 \cdot 7$ & $2 \cdot 3$ & $1 \cdot 7$ & $4 \cdot 7$ \\
\hline Mean & $7 \cdot 50$ & 3.00 & $0 \cdot 60$ & $3 \cdot 90$ & 8.99 & 1.89 & $1 \cdot 20$ & 5.82 \\
\hline SEM & 0.79 & $0 \cdot 26$ & $0 \cdot 18$ & $1 \cdot 06$ & $1 \cdot 17$ & $(0 \cdot 30$ & 0.44 & 1.45 \\
\hline
\end{tabular}

Percentage of swallows followed by aperistalsis

\begin{tabular}{lll} 
& Control period & Symptom period \\
\cline { 2 - 3 } Mean & 51.0 & $76 \cdot 1$ \\
SEM & 11.3 & 5.8 \\
\hline
\end{tabular}

Peri: peristaltic contractions: Sync: synchronous contractions: TI: totally inhibited swallows.

Note: Where symptoms occurred over more than one minute, values per minute were calculated from the total duration of symptoms.

during conventional manometry. The proportion of non-conducted swallows and synchronous contractions was much greater during eating than during conventional manometry in both our groups. Second, that eating produces symptoms in a significant number of patients. One third of our patients studied during eating experienced symptoms. Positive responses of up to $35 \%$ for the provocation of chest pain during acid perfusion ${ }^{14-21}$ and up to $30 \%$ after intravenous edrophonium ${ }^{19}{ }^{20}$ have been reported recently. Whilst these figures refer to the provocation of chest pain, however (which was found in four of 30 patients in our study), these provocative tests do not assess solid dysphagia, which can only be examined during eating. Nine of 30 patients experienced dysphagia while eating.

Manometric abnormalities seen in response to swallowing water are often assumed to indicate the cause of patients' symptoms but the differences in oesophageal motor patterns evoked by swallowing water and bread must cast doubt upon the validity of such extrapolation. Mellow ${ }^{22}$ studied the effect of eating and of swallowing water on oesophageal motility in five patients with known dysmotility and in 12 healthy volunteers. He too found a poor relationship between conventional manometry and fed

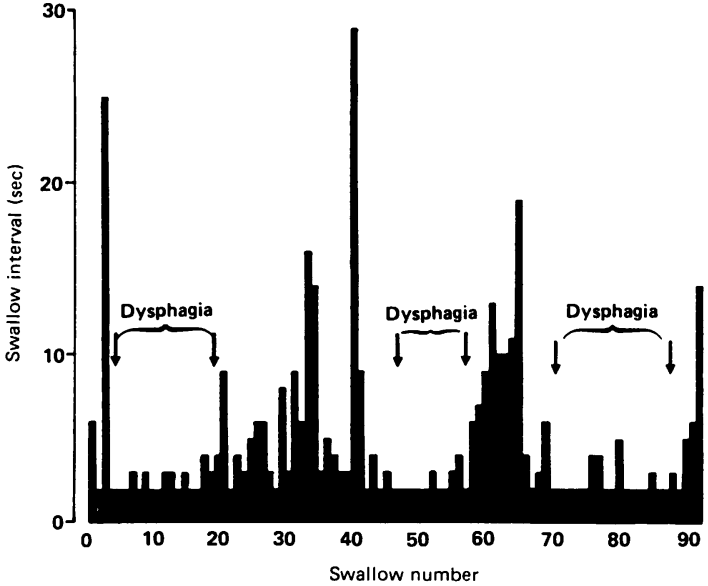

Fig. 4 Intervals between successive swallows while eating bread (patient 21). Onset and resolution of three distinct episodes of dysphagia are as shown.

patterns of oesophageal motility and observed a high incidence of both non-conducted swallows and synchronous contractions during eating in both normal subjects and patients.

Symptomatic motility disturbances are thought to be associated with either an increase in the amplitude or duration of peristaltic contractions or with increased synchronous activity. $1271: 22-2+$ In the study by Mellow, contractile patterns during eating were examined in five patients known to have motility disorders. Oesophageal dysmotility was accentuated on eating. Mellow's original study has now been extended, with manometry being performed during food ingestion in 100 consecutive patients with chest pain and/or dysphagia. ${ }^{25}$ Many of these patients had manometric abnormalities during conventional manometry with water swallows, however, whereas we have excluded such patients and studied those who either had normal conventional oesophageal function tests, or gastro-oesophageal reflux. None of our patients experienced symptoms during conventional manometry.

As shown in Figure 1, painful dysphagia in one of our patients was apparently caused by oesophageal 'spasm' in response to eating the bread - an abnormality which had not been apparent during manometry with swallowing water (Fig. 1). This patient thus displayed the classical type of positive response to a provocation test. In the other eight patients with dysphagia, however (three of whom also had pain during eating), symptoms were associated with aperistalsis. Non-propagated contractions and non-conducted swallows were more frequent during these periods. Direct observation of the 
patients suggested that loss of peristaltic activity preceded the perception of dysphagia or pain.

Inhibition of normal oesophageal peristalsis may have arisen as a result of rapid swallowing, through 'deglutitive inhibition'. This term has been used to refer to the inhibitory effect of one swallow on the contractile effects of a previous swallow but Vanek and Diamant ${ }^{26}$ recently studied the interactions between closely spaced paired water swallows in healthy volunteers, thereby extending previous studies of this phenomenon. ${ }^{27-24}$ They showed that there is, in fact, mutual interference between closely spaced paired swallows. The pattern of inhibition is critically dependent upon bolus size and the time interval between swallows. Swallow intervals of less than four seconds produce inhibition of a first contraction by a second swallow. As the swallow interval increases to between six and eight seconds the first wave is still arrested in its progress down the oesophagus, but the second contraction is replaced by a low amplitude non-peristaltic wave. During normal eating, bolus size and swallow interval must inevitably vary over short periods of time and small changes in swallow interval should therefore be expected to produce marked changes in contraction patterns, particularly with swallow intervals in the range of four to eight seconds. The small increase in mean swallow frequency we observed (from 7.5 to 9.0 per minute) would therefore be sufficient to explain the significant increase in the proportion of aperistaltic swallows seen during the symptomatic periods.

While aperistalsis might account for dysphagia, the cause of the discomfort, or pain, is less clear. Pain may have arisen, however, from oesophageal distension by boluses of bread. Recent studies have shown that balloon distension of the oesophagus may cause pain and that some patients seem to have a low threshold for the perception of stretch." Balloon distension of the proximal oesophagus also inhibits distal oesophageal motility. ${ }^{31}$

Gastro-oesophageal reflux must also be considered as a possible cause of pain during eating. Distal sphincter relaxation, aperistalsis and the semirecumbency of our patients would have predisposed to reflux. Indeed, nine of the 20 reflux patients experienced symptoms whilst eating compared with one of the 10 patients in group A. Against reflux as the cause of our patients' symptoms, however, is the fact that oesophageal acid instillation has been shown to enhance, not suppress peristaltic contractions.

Our results indicate a need for further study of oesophageal motor patterns during eating. Not only does eating provoke symptoms in a significant proportion of patients, but the importance of swallow frequency in relation to apparently abnormal patterns of esophageal motility has not hitherto received sufficient emphasis. It would appear that rapid swallowing during eating can cause aperistalsis and that this, in turn, can be associated with dysphagia, perhaps as cause and effect. This phenomenon is not recognised when swallow intervals are so timed as to avoid the occurrence of 'deglutitive inhibition' as in conventional diagnostic manometry.

\section{References}

1 De Cacstecker JS, Blackwell JN, Brown J, Heading RC. The oesophagus as a cause of recurrent chest pain: which patients should be investigated and which tests should be used? Lancet 1985; ii: 1143-6.

2 Brand DL. Martin D. Pope II CE. Esophageal manometries in patients with angina-like chest pain. Dig Dis Sci 1977: 2: 300-4.

3 Anonymous. Angina and ocsophageal discase [Editorial]. Lancet 1986; i: 191-2.

4 Clouse RE, Staiano A, Landau DW, Schlachter JL. Manometric findings during spontaneous chest pain in patients with presumed esophageal 'spasms'. Gastroenterology 1983; 85: 395-4()2.

5 Meyer GW, Castell DO. Human oesophageal response during chest pain induced by swallowing cold liquids. JAMA 1981; 246: 2057-9.

6 Siegel CI, Hendrix TR. Oesophageal motor abnormalities induced by acid infusion in patients with heartburn. $J$ Clin Invest 1963; 42: 686-95.

7 Benjamin SB, Richter JE, Cordova CM. Knuff TE, Castell DO. Prospective manometric evaluation with pharmacologic provocation of patients with suspected esophageal motility dysfunction. Gastroenterology 1983; 84: 893-901.

8 Mellow M. Symptomatic diffuse ocsophageal spasm: manometric follow-up and response to cholinergic stimulation and cholinesterase inhibition. Gastroenterology 1977; 73: 237-40.

9 London RL, Ouyang A, Snape WJ. Goldberg S. Hirshfeld JW. Cohen S. Provocation of esophageal pain by ergonovine or edrophonium. Gastroenterology 1981: 81: $10-4$.

10 Richter JE, Hackshaw BT, Wu WS, Castell DO. Edrophonium: a useful provocative test for esophageal chest pain. Ann Intern Med 1985; 103: 14-21.

11 Wexler RM. Kaye MD. Pentagastrin in diffuse oesophageal spasm. Gut 1981; 22: 213-6.

12 Dart AM, Davies A. Lowdnes RH, Dalal J, Ruttley M, Henderson AH. Oesophageal spasm and angina: diagnostic value of ergometrine (ergonovine) provocation. Eur Heart J 1980; 1: 91-5.

13 Alban Davies H, Kaye MD, Rhodes J, Dart AM, Henderson AH. Diagnosis of ocsophageal spasm by ergometrine provocation. Gut 1982; 23: 89-97.

14 Janssens J, Vantrappen G. Ghillebert G. 24-hour recording of esophageal pressure and $\mathrm{pH}$ in patients with noncardiac chest pain. Gastroenterology 1986; 90: 1978-84.

15 Peters L, Maas L, Petty D. Dalton C, Penner D, Wu W. 
Castell D, Richter J. Spontaneous noncardiac chest pain. Evaluation by 24-hour ambulatory esophageal motility and $\mathrm{pH}$ monitoring. Gastroenterology 1988; 94: 878-86.

16 Blackwell JN, Hannan WJ, Adam RD, Heading RC. Radionuclide transit studies in the detection of oesophageal dysmotility. Gut 1983; 24: 421-6.

17 Richter JE, Wu WC, Johns DN. Esophageal manometry in 95 healthy adult volunteers: variability of pressure with age and frequency of 'abnormal' contractions. Dig Dis Sci 1987; 32: 583-92.

18 Vantrapen G, Hellemans J. Studies on the normal deglutitive complex. Am J Dig Dis 1967; 12: 232-5.

19 Benjamin SB, Richter JE, Cordova CM, Knuff TE, Castell DO. Prospective manometric evaluation with pharmacologic provocation of patients with suspected esophageal motility dysfunction. Gastroenterology 1983; 84: 893-901.

20 Richter JE, Hackshaw BT, Wu WS, Castell DO. Edrophonium: a useful provocative test for esophageal chest pain. Ann Intern Med 1985; 103: 14-21.

21 De Caestecker JS, Pryde A, Heading RC. Comparison of iv edrophonium and esophageal acid perfusion during oesophageal manometry in patients with non-cardiac chest pain. Gut 1988; 29: 1029-34.

22 Mellow MH. Esophageal motility during food ingestion: a physiologic test of esophageal motor function. Gastroenterology 1983; 85: 570-7.

23 Benjamin SB, Gerhardt DC, Castell DO. High amplitude peristaltic esophageal contractions associated with chest pain and/or dysphagia. Gastroenterology 1979; 77: 478-83.

24 Creamer B, Donoghue E, Code CF. Pattern of esophageal motility in diffuse spasm. Gastroenterology
1958: 34: 782-92.

25 Allen ML, Orr WC, Mellow M, Robinson MG. Water swallows vs food ingestion as manometric tests for esophageal dysfunction. Gastroenterology 1988; 95: 831-3.

26 Vanek AW. Diamant NE. Responses of the human esophagus to paired swallows. Gastroenterology 1987; 92: $643-50$.

27 Hellemans J, Vantrappen G, Janssens J. Electromyography of the esophagus. 4. The deglutitive inhibition. In: Vantrappen G, Hellemans J, eds. Diseases of the esophagus. New York: Springer-Verlag. 1974: 280-4.

28 Meyer GW, Gerhardt DC, Castell DO. Human esophageal response to rapid swallowing: muscle refractory period or neural inhibition? Am J Physiol 1981; 241: G129-36.

29 Ask P. Tibbling L. Effect of time interval between swallows on esophageal peristalsis. Am J Physiol 1980; 238: G485-90.

30 Richter JE, Barish CF, Castell DO. Abnormal sensory perception in patients with esophageal chest pain. Gastroenterology 1986; 91: 845-52.

31 Kendall GPN, Thompson DG, Day SJ, Garvic N. Motor responses of the oesophagus to intraluminal distension in normal subjects and patients with oesophageal clearance disorders. Gut 1987; 28: 272-9.

32 Kjellen G, Tibbling L. Oesophageal motility during acid-provoked heartburn and chest pain. Scand $J$ Gastroenterol 1985; 20: 937-40.

33 Siegel CI, Hendrix TR. Esophageal motor abnormalities induced by acid perfusion in patients with heartburn. J Clin Invest 1963; 42: 686-95.

34 Atkinson M, Bennett JR. Relationship between motor changes and pain during esophageal acid perfusion. Am J Dig Dis 1968; 13: 346-50. 